\title{
State of the Art: Immersive Technologies for Perioperative Anxiety, Acute, and Chronic Pain Management in Pediatric Patients
}

\author{
Mohammad Alqudimat $^{1,2} \cdot$ Giulia Mesaroli $^{2,3} \cdot$ Chitra Lalloo $^{2} \cdot$ Jennifer Stinson ${ }^{1,2,4} \cdot$ Clyde Matava $^{4,5}$ (D)
}

Accepted: 2 June 2021 / Published online: 14 July 2021

(C) The Author(s), under exclusive licence to Springer Science+Business Media, LLC, part of Springer Nature 2021

\begin{abstract}
Purpose of Review This review summarizes and provides a comprehensive narrative synthesis of the current evidence on immersive technology's (i.e., virtual and augmented Reality) use for perioperative anxiety, acute, and chronic pain in pediatrics. Recent Findings Researchers have increasingly studied immersive technology as a non-pharmacological alternative for perioperative anxiety, acute, and chronic pain management. We found several research studies published over the last 3 years: almost all studies examined the use of virtual reality for perioperative anxiety and pain; only one case report was about the use of augmented reality for preoperative anxiety. Most studies showed that virtual reality intervention is effective and safe for perioperative anxiety, acute, and chronic pain. However, the studies are heterogeneous with relatively small sample sizes.

Summary This review shows that more high-quality studies (i.e., randomized controlled trials with larger sample sizes and standardized methods for measuring and reporting outcomes) are needed to examine the effectiveness and adverse effects of virtual reality intervention on perioperative anxiety, acute, and chronic pain in pediatrics.
\end{abstract}

Keywords Immersive technology $\cdot$ Virtual reality $\cdot$ Augmented reality $\cdot$ Preoperative anxiety $\cdot$ Postoperative acute and chronic pain $\cdot$ Procedural pain

\section{Introduction}

Anesthesia and surgical procedures impose a potential stressor for pediatric patients, leading to significant perioperative fear and distress. Up to $64 \%$ of children experience a high level of preoperative anxiety [1-5]. Before surgery, pediatric patients may feel threatened by the expected parental separation,

Clyde Matava

clyde.matava@sickkids.ca

1 Lawrence S. Bloomberg Faculty of Nursing, University of Toronto, 155 College Street, Suite 130, Toronto, ON M5T 1P8, Canada

2 Child Health Evaluation Sciences, Research Institute, The Hospital for Sick Children, 555 University Avenue, Toronto, ON M5G 1X8, Canada

3 Department of Rehabilitation Services, The Hospital for Sick Children, 555 University Avenue, Toronto, ON M5G 1X8, Canada

4 Department of Anesthesia and Pain Medicine, The Hospital for Sick Children, 555 University Avenue, Toronto, ON M5G 1X8, Canada

5 Temerty Faculty of Medicine, Department of Anesthesiology and Pain Medicine, University of Toronto, 123 Edwards Road,

Toronto, ON M5G 1E2, Canada unfamiliar environment, new faces with masks on, alarm sounds, and high level of parental anxiety, which can be because of the procedure or their children's fear [3, 4, 6-9]. Ineffective preoperative anxiety management may increase postoperative pain, delirium, analgesic consumption, general anxiety, behavioral problems, and difficulty sleeping $[5,8$, 10]. Therefore, alleviating children's preoperative anxiety can improve recovery, mitigate postoperative pain, and improve the overall perioperative experience. Further, up to $30-40 \%$ of children experience moderate to severe postoperative pain [11-13] and are at risk for transition to chronic pain, a debilitating and costly public health problem [14-17]. Unrelieved or undertreated pediatric pain can negatively impact all domains of health-related quality of life and also interferes with normative developmental tasks [18-22].

Recent research shows that immersive technology, particularly virtual reality (VR), is an effective intervention to alleviate perioperative anxiety and pain in children [23-31]. Immersive technology, namely VR and augmented reality (AR), refers to technology that aims to extend an individual's sensory environment by emulating or simulating physical reality through technology [32]. VR transposes users to an alternative setting and or a fully digital three-dimensional visualization, which creates 
a sense of immersion by allowing them to interact with the virtual environment $[33,34]$. AR enhances an existing physical environment with additional virtual objects embedded in that space (i.e., additional digital information layers) [32, 35].

Over the past years, several review studies have been published about the effect of VR intervention on anxiety, acute, and chronic pain in the pediatric population. These reviews incorporate various medical procedures (e.g., dental care, burn, venipuncture, chemotherapy administration, and various surgical procedures) $[29,44,45]$, focus on preoperative anxiety in adult and pediatrics [30], or assess the use of VR distraction interventions for children with acute pain in any healthcare setting [36•]. None of these reviews concentrated on the perioperative anxiety, acute, and chronic pain in children. In this review [46], we summarize the findings of the most recent evidence, i.e., studies that have been published in the past 3 years, on the effect of immersive technology on perioperative anxiety, acute, and chronic pain in pediatric patients.

\section{Search Strategy and Selection Criteria}

We searched PubMed, Google Scholar and Google (for gray literature), and the Cochrane database using the following search terms: "immersive technology," "perioperative," "perioperative care," "anxiety," "pain management," "pediatric or pediatrics or paediatric or Paediatrics," "children," "children surgery," "child," "child surgery," "immersive technology*," "virtual reality*," "augmented reality*," "perioperative*," "preoperative*," "postoperative*," "surgery* or after surgery*," "anxiety*," "pain*," "pain management*," "pediatric*," "paediatric*," and "Child." We reviewed papers that have published since January 1, 2017. Articles were also identified through the authors' reference lists of selected articles (e.g., systematic review and meta-analysis) found in the literature search. Papers published in English were reviewed. The final reference list was generated based on originality and relevance to this narrative review's broad scope.

\section{Immersive Technology and Preoperative Anxiety in Children}

We identified eight RCTs that investigated the effect of VR on alleviating preoperative anxiety in pediatrics from 5 countries: South Korea $(n=4)$, Iran $=(n=1)$, Netherlands $(n=1)$, The USA $(n=1)$, and Japan $(n=1)$ (Table 1). In six RCTs [28, 37-40, 47], researchers used VR as exposure (i.e., VR tour of the operating room) to allow pediatric patients to become familiar with the operating room before induction of anesthesia. Two RCT examined the use of VR as a distraction tool [48, 49]. Hashimoto et al. (2020) asked pediatric patients $(n=29)$ to practice how to use the VR headset the day before the surgery by watching their favorite cartoon animation, and on the day of the surgery, the researchers ask them to use the VR headsets again while staying in the pre-anesthetic holding area until after the induction of anesthesia. In the other RCTs, researchers asked the participants to use VR just before the surgery, of which, the exact timing was reported in three RCTs as $1 \mathrm{~h}$ before entering the OR [37, 38, 47]. In most RCTs (7/8), the modified Yale Preoperative Anxiety Scale [50] was used to measure the preoperative anxiety, while in one RCT, the Yale Preoperative Anxiety Scale [51] was used.

Almost all RCTs compared VR (i.e., intervention group) with care as usual (i.e., control group), except for one RCT [47]. In that RCT, Park et al. examined the effectiveness of VR as exposure to the operating room on preoperative anxiety for both patients and their parents. The researchers asked parents $(n=40)$ in the intervention group to watch a 4-min VR tour concurrently with their children (i.e., mirroring display) while escorted from the pre-anesthetic holding area to the operating room. Parents and children were able to talk with each other and discuss what they were seeing. The results showed that the preoperative anxiety scores for children and their parents were significantly lower in the intervention group than the control group (i.e., children watched the same tour alone; $n=40$ ).

Although the reviewed RCTs are heterogeneous (i.e., content and duration of VR intervention, timing of administering the intervention, sample size, different mechanisms of VR, and type of surgery), almost all RCTs (7/8) showed that the preoperative anxiety score was significantly lower in the VR groups than in the control groups. Several limitations were reported in these studies including most of the RCT was open-label or not blinded [39, 48, 49] and repeated measures analysis of variance (i.e., ANOVA) was not used for comparison groups in all studies since the data was not normally distributed, technical issues (e.g., battery depletion), and small sample sizes. Only one RCT by Eijlers et al. showed that there was no significant difference in preoperative anxiety scores between the intervention group (i.e., VR exposure tour to the operating room) and the control group (i.e., "care as usual"). The researchers highlighted in the limitation section that $22 \%$ (21/94) of children in the intervention group discontinued the VR by frequently taking off the headset. Most of these children $(15 / 21)$ were 4 or 5 years old, and the headset may have been large and heavy on them.

We identified two case studies from the USA $[52,53]$ and one game development study from Belgium [54]. Libaw et al. described the use of $\mathrm{AR}$ as a distraction technique during the induction of general anesthesia in a case study of three children (mean age $=8.7$ ). The AR software was designed to show the real operating room with an avatar that encourages patients to take deep breaths during mask induction. The researchers reported that patients felt less anxiety in comparison with their 


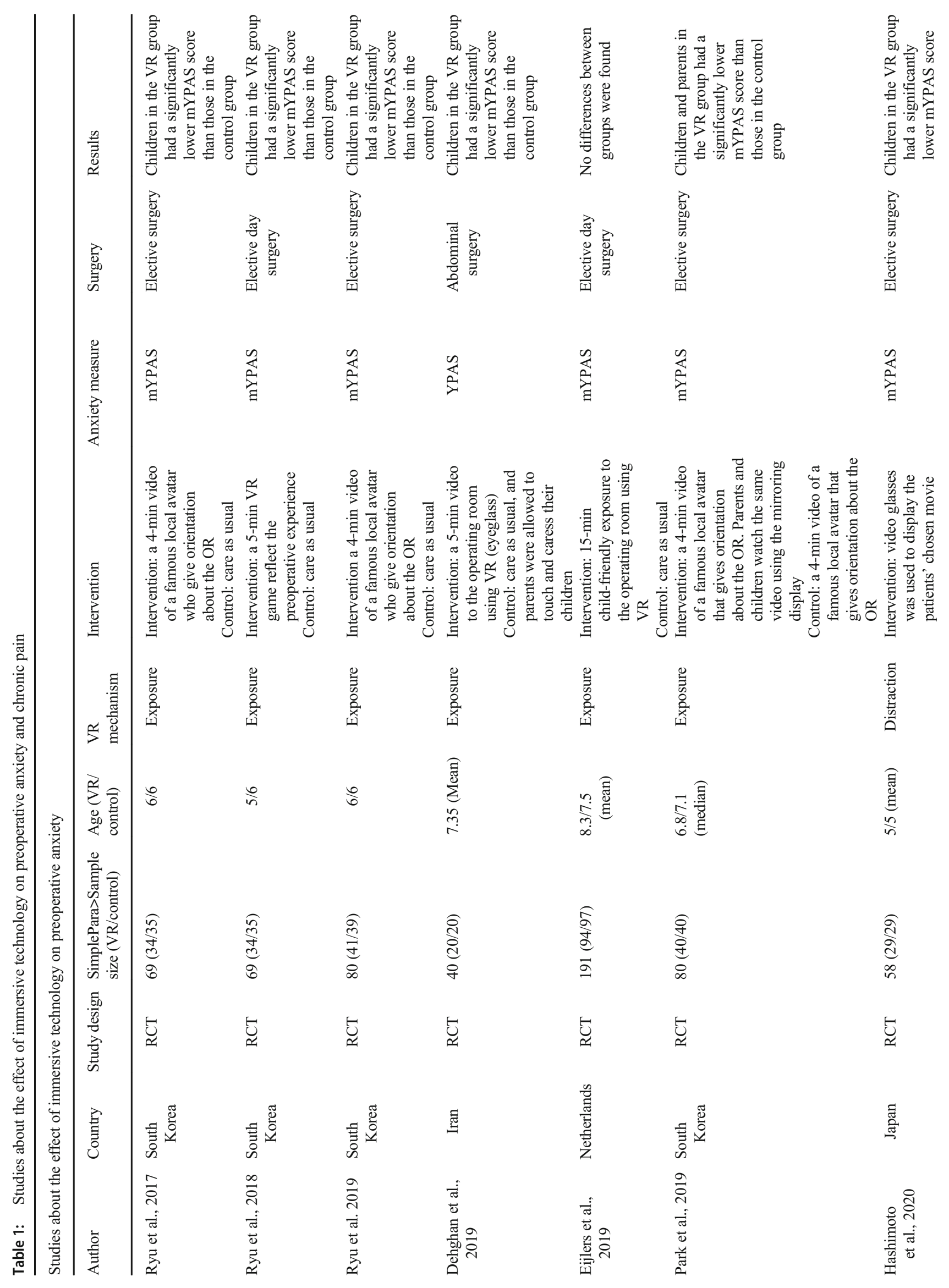




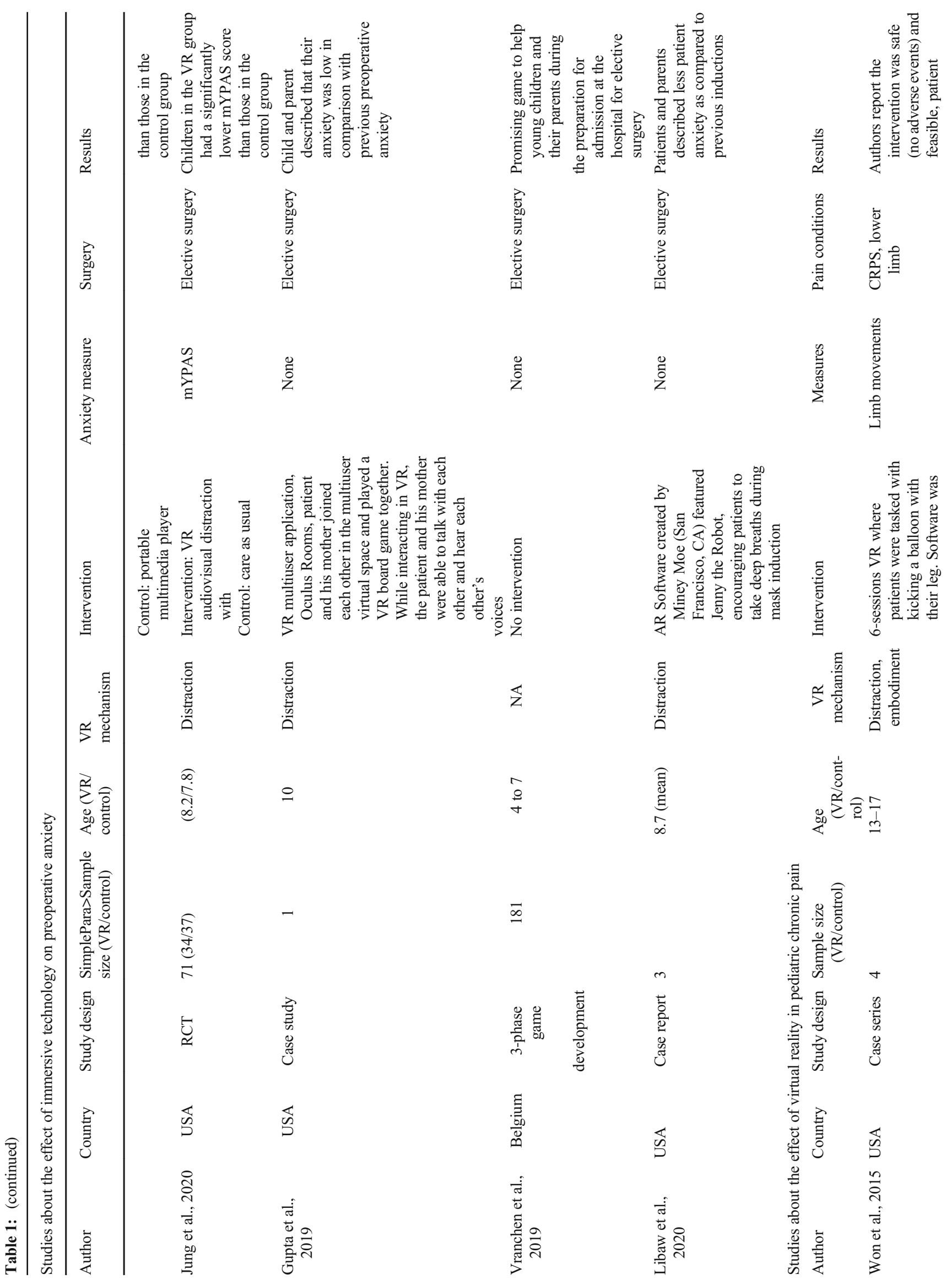




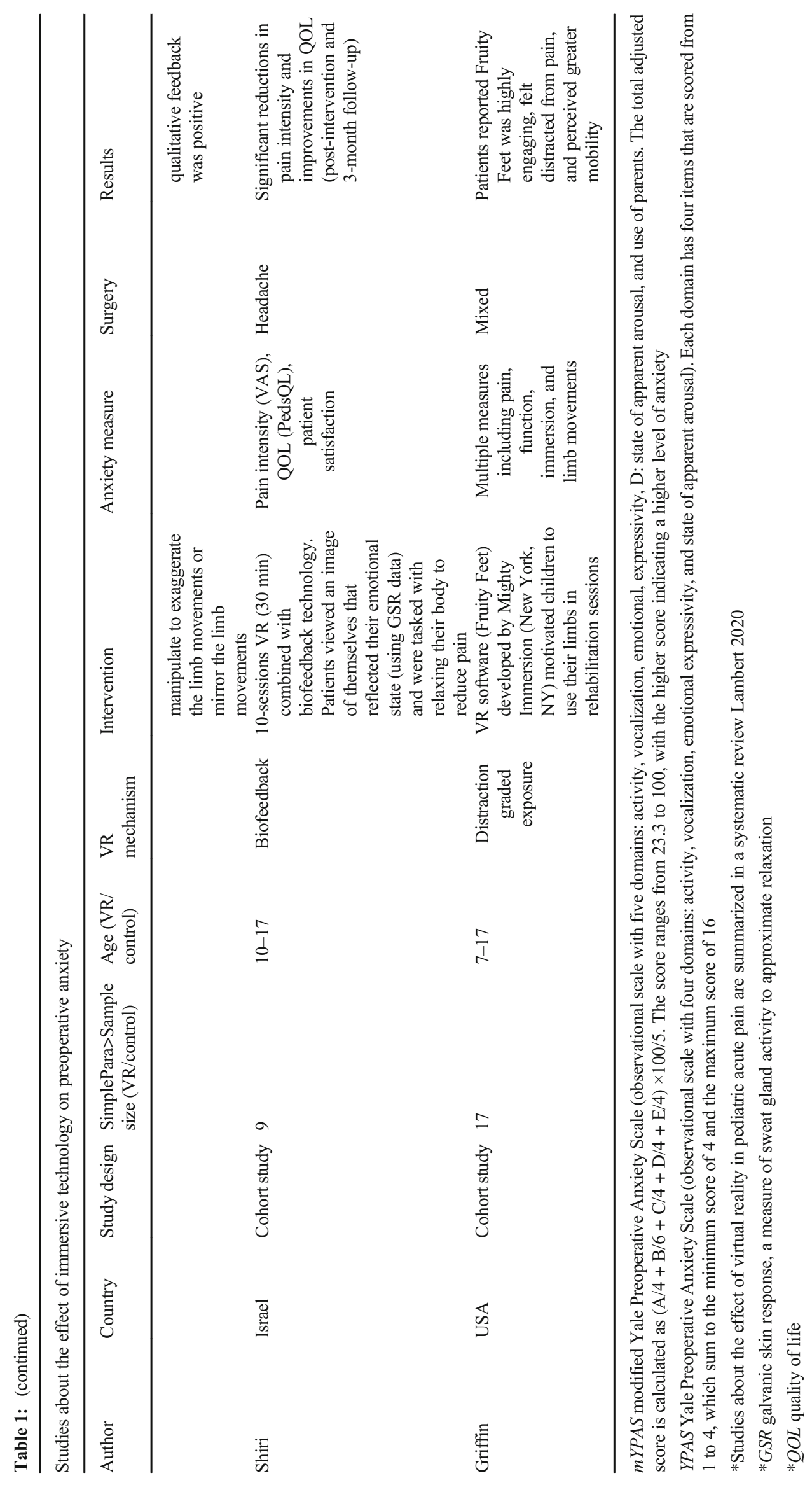


previous experience. In the second case study by Gupta et al., the researchers used a VR multiuser application, Oculus Rooms, which allowed a 10 -year-old patient $(n=1)$ and his mother to play and interact together virtually during patient transportation from the preoperative area to the operating room. The patient and his mother were able to hear and talk to each other. The researchers concluded that this approach of using VR reduced the child's preoperative anxiety by keeping the childparent connection until anesthesia induction. Finally, Vrancken et al. developed and tested a game, "HospiAvontuur," to help children (4-7 years) and their parents prepare for elective surgery admission.

The current evidence showed that immersive technology (i.e., VR and AR) is a promising intervention to alleviate preoperative anxiety in children. Further RCTs with larger sample sizes and standardized protocol (e.g., multicenter $\mathrm{RCT}$ ) are needed to establish evidence (i.e., with high-certainty) on immersive technology and its effect and adverse effects on preoperative anxiety. This is crucial since suboptimal management of preoperative anxiety can intensify postoperative pain.

\section{Immersive Technology in Acute and Procedural Pain}

Immersive technologies in the pediatric acute and procedural pain setting have largely focused on VR technologies for children undergoing needle pokes, wound, or burn dressing changes [36 $]$. Distraction and affect modulation are the purported mechanisms that drive the effectiveness of VR interventions in the context of acute and procedural pain. Distraction through VR allows children experiencing pain to shift their attentional resources towards stimuli in VR, producing a hypoalgesic effect. VR can also stimulate a positive affective state, enhancing distraction and hypoalgesia [41••]. In a recent Cochrane review, Lambert et al. reviewed 17 RCTs and concluded that there is little evidence for the use of VR in reducing acute pain in children; the effectiveness of VR intervention on acute pain in children undergoing clinical treatments and procedures has been ranked as low to very low certainty [36•]. Therefore, they highlighted that there is a need for larger high-quality RCTs (i.e., at least 200 participants in each arm) to investigate the effectiveness and the adverse effect of VR intervention in this population.

\section{Immersive Technology in Chronic Pain Management}

The role of immersive technologies in pediatric chronic pain is not only to provide distraction from pain, but also uses biofeedback, graded exposure, and motivation [55, 56]. Physical activity for children with chronic pain is often painful and avoided [57]. Engaging in physical activity using immersive technology while distracted from pain may be better tolerated. Graded exposure is utilized to overcome fear of pain and gradually improve physical function over time [58]; this can be employed through VR with modifiable gaming parameters gradually expose children to exercises. Technology with features such as music, cues, rewards, and performance metrics can provide motivation to perform painful movements. Technology that uses biofeedback provides patients information about a physiological parameter to prompt behavior modification, such as the VR application DEEP [59]. DEEP is a biofeedback, meditative, and psychoactive VR game that is controlled by breathing. Users don the VR headset and following onscreen and biofeedback cues, allow the game to teach them breathing techniques that can relieve stress, anxiety, and mild depression

Immersive technologies in pediatric chronic pain are an emerging practice and science, heavily focused on VR. Evidence from studies of VR in adults with chronic pain show promising results. A scoping review (research methodology that provides an overview of the available research evidence without necessarily producing a summary answer to a discrete research question) [60] and systematic review [61] of controlled trials evaluating VR in adults with chronic pain report that VR is effective in pain reduction and functional improvements, but there is insufficient data to show long-lasting effects.

There are a handful of studies evaluating VR in pediatric chronic pain. Won et al. conducted a pilot study evaluating VR for children $(n=4)$ with complex regional pain syndrome [62]. VR was used to engage the children in lower limb exercises (6 sessions) and used motion sensors to track limb movements during the intervention. The authors conclude that VR was well tolerated and feasible to use; however, in the absence of a comparator group, it is unclear whether VR enhanced limb movements compared to traditional forms of exercise. Shiri et al. conducted a pilot feasibility study in children with headaches $(n=9)$ using VR (10 sessions) for biofeedback targeting relaxation [63]. In addition to feasibility, pre-post measures demonstrated improvements in pain intensity and quality of life post-intervention [63], although unclear if this differs from other biofeedback technologies.

Griffin et al. conducted a pre-post study of using a customdeveloped VR technology (Fruity Feet) with 17 youths with chronic pain (63 sessions total) in the rehabilitation setting [56]. Fruity Feet uses gaming features to motivate children to engage in physical activity; game settings can be manipulated to target the painful body part. The authors report that VR was safe to use and achieved high levels of patient satisfaction and improvements in pain and function post intervention. Mesaroli et al. (unpublished study) implemented Fruity Feet in Canada with a cohort of youth $(n=8)$ with chronic pain 
in the context of physiotherapy, and similarly reported high levels of physiotherapist and patient acceptance and feasibility.

Current evidence for VR in pediatric chronic pain, although limited, is promising. Future studies are needed to evaluate the effectiveness of VR in reducing pain or improving function, ideally through controlled trials comparing VR to standard of care. The INOVATE-Pain consortium has outlined guiding principles for VR interventions in pediatric chronic pain with suggested measures and study procedures $[41 \bullet \bullet, 64]$. This is critical so comparisons across studies, such as through a systematic review, will be possible. Furthermore, in the context of the COVID-19 pandemic and the shift towards virtual care for chronic pain management [23], the future of immersive technologies should shift accordingly to remote delivery. Adapting VR for at-home use is currently underway through a collaboration with The Hospital for Sick Children in Toronto, Canada, and Stanford Chariot VR in California, USA, funded by Johnson and Johnson.

\section{Mechanism of Action of Immersive Technology in the Pediatric Population}

Researchers have postulated the effect of VR on perioperative anxiety and pain by two mechanisms: exposure and distraction $\left[30,36^{\circ}\right]$. VR can expose patients and their parents to the perioperative settings (e.g., operating room and recovery area), which allows them to become familiar with the physical environment. The findings of recent randomized controlled trials (RCTs) showed that VR was effectively used as exposure therapy to reduce children's preoperative anxiety (5 to 8 years old) [28, 37-40]. On the other hand, VR can distract and divert pediatric patients' attention away from stressful or painful procedures with engaging materials and direct patients' attention to more pleasant stimulus [36 ${ }^{\bullet}$. This is because children can be captivated by audiovisual content. In a recent review study [41••], Trost et al. described the VR approaches to pain and discussed the three interrelated dimensions of VR; these dimensions are frequently described as the three key features or pillars of VR [42]: presence, immersion, and interactivity. Presence is the "subjective experience of being in one place or environment, even when one is physically situated in another" [43]. Immersion refers to the user's sense of being engaged and captivated by the digital audiovisual content $[41 \bullet \bullet]$. Interactivity is the user's ability to interact and manipulate the virtual space using the technical configuration [41••]. Trost et al. suggested a model (i.e., heuristic model) that can be used as a framework for future VR pain research focusing on VR mechanisms [41••]. This model indicates that VR pain applications can be investigated from the perspective of having VR hardware and software, which enable the production of the pillars of VR. The pillars of VR moderate and mediate the subsequent changes in the users' cognitive, emotional, social, behavioral, and physiological outcomes (i.e., targets of pain-related therapy), leading to more considerable outcomes such as reduced pain intensity $[41 \bullet \bullet]$. Using such a standardized conceptual framework in future research may facilitate reflective and purposeful progress in the immersive technology pain field, which enhances the methodological consistency across studies.

\section{Challenges in Establishing Immersive Technologies in the Pediatric Population}

Despite the advance of immersive reality, several challenges exist limiting its use in routine pediatric care [65]. The availability of age-, patient-, and culturally appropriate VR applications, size and weight of the headsets, patient isolation status, and infection control consideration are factors' this group of authors have encountered with clinical and research implementation [65]. The development of VR environments can be costly and requires a team of experts to execute. Pediatric centers may leverage lowcost alternatives such as 360 video environments [65]. Also, the pediatric centers may identify industry partnerships and collaborations to leverage co-design and co-development. The headsets' size may cause headaches and eye aches as most devices' interpupillary distance is designed for older children and adults. As such, most headset developers recommend children over 8 years old to use VR. However, there has been no evidence provided on the effects of VR on younger children. As a result, concerns regarding the use of VR in younger children still exist. The COVID-19 pandemic highlighted the risks of disease transmission and further underlined the importance of infection control during VR among patients. Our institution developed protocols for cleaning devices that include single-use disposable covers, non-fabric headsets, wiping processes, and the use of UV light for disinfecting VR devices and partnering with infection prevention experts was critical. The use of Google Cardboard VR headsets that are single-use can also mitigate infection risk as patients can keep their own devices [65]. Similarly, dedicated reusable devices for the duration of a patient's hospital encounter can be used following consultation with infection control experts and approved cleaning processes.

\section{Conclusions}

The current evidence on immersive technology in pediatric perioperative anxiety, acute, and chronic pain is promising despite the limitation of VR technology and current studies. Immersive technology for anxiety and pain in children is a relatively new field driven by rapid technological advancements. Thus, more high-quality RCTs with large sample sizes are needed to investigate the effectiveness and adverse effects 
of VR intervention on perioperative anxiety, acute, and chronic pain in pediatrics. Further, standardized theoretical frameworks that facilitate the design of VR trials, the measurement, and reporting of outcomes are essential. In addition, these efforts should include the comparison of VR with other types of technology like AR.

Given the COVID-19 pandemic, we also recommend research on the role of immersive technology for managing in pain using remote VR by children at home.

\section{Acknowledgements SickKids Virtual Reality Program.}

\section{Declarations}

Conflict of Interest Mohammad Alqudimat declares that he has no conflict of interest.

Giulia Mesaroli is co-investigator on a virtual reality grant funded by Johnson \& Johnson, and is co-investigator on a virtual reality grant funded by Physician Services, Inc.

Chitra Lalloo is co-investigator on a virtual reality grant funded by Johnson \& Johnson, and is co-chair of research for the SickKids Pain Centre. This is an unpaid position and involves leadership of pain-related research initiatives across The Hospital for Sick Children (Toronto, Canada).

Jennifer Stinson is the principal investigator on a virtual reality grant funded by Johnson \& Johnson; is co-principal investigator on a virtual reality grant funded by Physician Services, Inc.; is co-investigator on a virtual reality grant funded by Stanford University; is co-investigator on a virtual reality grant funded by Women and Children's Health Research Institute (WCHRI); is a consultant for Sickle Cell Disease Pain Working Group, Development of Pain PRO Measures, PhenX Toolkit (consensus measures for Phenotypes and eXposures, https://www.phenxtoolkit.org); speaker's honoraria from the Society of Pediatric Psychology and St. Jude Children's Research Hospital; is a member, International Association for Study of Pain (IASP) Presidential Task Force on COVID-19 and Pain (2021); Councilor, IASP (2020-2026); member, Scientific Program Committee, IASP 18th World Congress on Pain Meeting (2020); member, Patient Engagement Committee, the Chronic Pain Network (2020present); co-Director of the SickKids Pain Centre (2019-present); cochair, Chronic Pain Registry Task Force, Ontario Ministry of Health Chronic Pain Network (2019-present); member, Informatics Committee for the Centre of Excellence for Chronic Pain in Canadian Veterans (2019-2024); and member, Global Alliance of Partners for Pain Advocacy (GAPPA) Task Force, IASP (2019-present).

Clyde Matava declares that he has no conflict of interest.

\section{References}

Papers of particular interest, published recently, have been highlighted as:

- Of importance

• Of major importance

1. Corman HH, Hornick EJ, Kritchman M, Terestman N. Emotional reactions of surgical patients to hospitalization, anesthesia and surgery. Am J Surg. 1958;96(5):646-53. https://doi.org/10.1016/ 0002-9610(58)90466-5.
2. Melamed BG, Siegel LJ. Reduction of anxiety in children facing hospitalization and surgery by use of filmed modeling. J Consult Clin Psychol. 1975;43(4):511-21. https://doi.org/10.1037/ h0076896.

3. Kain ZN, Mayes LC, O'Connor TZ, Cicchetti DV. Preoperative anxiety in children. Predictors and outcomes. Arch Pediatr Adolesc Med. 1996;150(12):1238-45. https://doi.org/10.1001/ archpedi.1996.02170370016002.

4. Davidson AJ, Shrivastava PP, Jamsen K, Huang GH, Czarnecki C, Gibson MA, et al. Risk factors for anxiety at induction of anesthesia in children: a prospective cohort study. Paediatr Anaesth. 2006;16(9):919-27. https://doi.org/10.1111/j.1460-9592.2006. 01904.x

5. Perrott C, Lee CA, Griffiths S, Sury MRJ. Perioperative experiences of anesthesia reported by children and parents. Paediatr Anaesth. 2018;28(2):149-56. https://doi.org/10.1111/pan.13300.

6. Schwartz BH, Albino JE, Tedesco LA. Effects of psychological preparation on children hospitalized for dental operations. J Pediatr. 1983;102(4):634-8. https://doi.org/10.1016/s00223476(83)80211-x.

7. Wright KD, Stewart SH, Finley GA, Buffett-Jerrott SE. Prevention and intervention strategies to alleviate preoperative anxiety in children: a critical review. Behav Modif. 2007;31(1):52-79. https://doi. org $/ 10.1177 / 0145445506295055$.

8. Fortier MA, Del Rosario AM, Martin SR, Kain ZN. Perioperative anxiety in children. Paediatr Anaesth. 2010;20(4):318-22. https:// doi.org/10.1111/j.1460-9592.2010.03263.x.

9. Davidson A, McKenzie I. Distress at induction: prevention and consequences. Curr Opin Anaesthesiol. 2011;24(3):301-6. https:// doi.org/10.1097/ACO.0b013e3283466b27.

10. Kain ZN, Mayes LC, Caldwell-Andrews AA, Karas DE, McClain BC. Preoperative anxiety, postoperative pain, and behavioral recovery in young children undergoing surgery. Pediatrics. 2006;118(2): 651-8. https://doi.org/10.1542/peds.2005-2920.

11. Kankkunen P, Vehviläinen-Julkunen K, Pietilä AM, Kokki H, Halonen P. Parents' perceptions and use of analgesics at home after children's day surgery. Paediatr Anaesth. 2003;13(2):132-40. https://doi.org/10.1046/j.1460-9592.2003.00998.x.

12. Hegarty M, Calder A, Davies K, Shave M, Christiansen E, Meyer $\mathrm{T}$, et al. Does take-home analgesia improve postoperative pain after elective day case surgery? A comparison of hospital vs parentsupplied analgesia. Paediatr Anaesth. 2013;23(5):385-9. https:// doi.org/10.1111/pan.12077.

13. Walther-Larsen S, Aagaard GB, Friis SM, Petersen T, MollerSonnergaard J, Romsing J. Structured intervention for management of pain following day surgery in children. Paediatr Anaesth. 2016;26(2):151-7. https://doi.org/10.1111/pan.12811.

14. Canadian Pain Task Force. Chronic Pain in Canada: Laying a Foundation for Action. https://www.canada.ca/en/health-canada/ corporate/about-health-canada/public-engagement/externaladvisory-bodies/canadian-pain-task-force/report-2019.html. Accessed 26-2 2021.

15. Holley AL, Wilson AC, Palermo TM. Predictors of the transition from acute to persistent musculoskeletal pain in children and adolescents: a prospective study. Pain. 2017;158(5):794-801. https:// doi.org/10.1097/j.pain.0000000000000817.

16. Rabbitts JA, Fisher E, Rosenbloom BN, Palermo TM. Prevalence and Predictors of Chronic Postsurgical Pain in Children: A Systematic Review and Meta-Analysis. J Pain. 2017;18(6):60514. https://doi.org/10.1016/j.jpain.2017.03.007.

17. Rabbitts JA, Palermo TM, Lang EA. A Conceptual Model of Biopsychosocial Mechanisms of Transition from Acute to Chronic Postsurgical Pain in Children and Adolescents. J Pain Res. 2020;13:3071-80. https://doi.org/10.2147/jpr.S239320.

18. Forgeron PA, King S Fau - Stinson JN, Stinson Jn Fau - McGrath PJ, McGrath Pj Fau - MacDonald AJ, MacDonald Aj Fau - 
Chambers CT, Chambers CT. Social functioning and peer relationships in children and adolescents with chronic pain: A systematic review. 2010(1203-6765 (Print)).

19. Palermo TM, Law E Fau - Churchill SS, Churchill Ss Fau - Walker A, Walker A. Longitudinal course and impact of insomnia symptoms in adolescents with and without chronic pain. 2012(15288447 (Electronic)).

20. Zernikow B, Wager J, Fau-Hechler T, Hechler T, Fau-Hasan C, Hasan C, Fau-Rohr U, Rohr U, Fau-Dobe M, Dobe M, FauMeyer A et al. Characteristics of highly impaired children with severe chronic pain: a 5-year retrospective study on 2249 pediatric pain patients. 2012(1471-2431 (Electronic)).

21. Noel M, Groenewald CB, Fau-Beals-Erickson SE, Beals-Erickson SE, Fau-Gebert JT, Gebert JT, Fau-Palermo TM, Palermo TM. Chronic pain in adolescence and internalizing mental health disorders: a nationally representative study. 2016(1872-6623 (Electronic)).

22. Rabbitts JA, Holley AL, Groenewald CB, Palermo TM. Association Between Widespread Pain Scores and Functional Impairment and Health-Related Quality of Life in Clinical Samples of Children. 2016(1528-8447 (Electronic)).

23. D'Alessandro LN, Brown SC, Campbell F, Ruskin D, Mesaroli G, Makkar M, et al. Rapid mobilization of a virtual pediatric chronic pain clinic in Canada during the COVID-19 pandemic. Canadian Journal of Pain. 2020;4(1):162-7. https://doi.org/10.1080/ 24740527.2020.1771688.

24. Eccleston C, Blyth FM, Dear BF, Fisher EA, Keefe FJ, Lynch ME et al. Managing patients with chronic pain during the COVID-19 outbreak: considerations for the rapid introduction of remotely supported (eHealth) pain management services. 2020(1872-6623 (Electronic))

25. Liossi C, Johnstone L, Lilley S, Caes L, Williams G, Schoth DE. Effectiveness of interdisciplinary interventions in paediatric chronic pain management: a systematic review and subset meta-analysis. $\mathrm{Br}$ J Anaesth. 2019;123(2):e359-e71. https://doi.org/10.1016/j.bja. 2019.01.024.

26. Peng P, Stinson JN, Choiniere M, Dion D, Intrater H, Lefort S, et al. Dedicated multidisciplinary pain management centres for children in Canada: the current status. Journal Canadien D'anesthesie. 2007;54(12):985-91. https://doi.org/10.1007/bf03016632.

27. Birnie KA, Dib K, Ouellette C, Dib MA, Nelson K, Pahtayken D, et al. Partnering For Pain: a Priority Setting Partnership to identify patient-oriented research priorities for pediatric chronic pain in Canada. CMAJ open. 2019;7(4):E654-e64. https://doi.org/10. 9778/cmajo.20190060.

28. Eijlers R, Dierckx B, Staals LM, Berghmans JM, van der Schroeff MP, Strabbing EM, et al. Virtual reality exposure before elective day care surgery to reduce anxiety and pain in children: A randomised controlled trial. Eur J Anaesthesiol. 2019;36(10):72837. https://doi.org/10.1097/eja.0000000000001059.

29. Ioannou A, Papastavrou E, Avraamides MN, Charalambous A. Virtual reality and symptoms management of anxiety, depression, fatigue, and pain: a systematic review. SAGE Open Nursing. 2020;6:2377960820936163.

30. Koo C-H, Park J-W, Ryu J-H, Han S-H. The Effect of Virtual Reality on Preoperative Anxiety: A Meta-Analysis of Randomized Controlled Trials. J Clin Med. 2020;9(10):3151.

31. Olbrecht VA, T O'Conor K, Williams SE, Boehmer CO, Marchant GW, Glynn SM, et al. Transient reductions in postoperative pain and anxiety using virtual reality in children. Medrxiv. 2020.

32. Pavithra A, Kowsalya J, Keerthi Priya S, Jayasree G, Nandhini TK. An Emerging Immersive Technology-A Survey. International Journal of Innovative Research In Technology. 2020;6(8):119-30.

33. Székely G, Satava RM. Virtual reality in medicine. Interview by Judy Jones. BMJ. 1999;319(7220):1305. https://doi.org/10.1136/ bmj.319.7220.1305.
34. Gandolfi E. Virtual Reality and Augmented Reality. Handbook of Research on K-12 Online and Blending Learning. 2nd ed., 2018.

35. Sidiq M, Lanker T, Makhdoomi K. Augmented Reality VS Virtual Reality. Int J Comput Sci Mob Comput. 2017;6(6):324-7.

36• Lambert V, Boylan P, Boran L, Hicks P, Kirubakaran R, Devane $D$, et al. Virtual reality distraction for acute pain in children. Cochrane Database Syst Rev. 2020;(10) This is an important systematic review followed rigorous methodology to identify research studies about VR distraction for acute pain in children and provides research and clinical recommendations. The authors concluded that further high-quality research is needed in the field.

37. Ryu JH, Park SJ, Park JW, Kim JW, Yoo HJ, Kim TW, et al. Randomized clinical trial of immersive virtual reality tour of the operating theatre in children before anaesthesia. Br J Surg. 2017;104(12):1628-33. https://doi.org/10.1002/bjs.10684.

38. Ryu JH, Park JW, Nahm FS, Jeon YT, Oh AY, Lee HJ, et al. The Effect of Gamification through a Virtual Reality on Preoperative Anxiety in Pediatric Patients Undergoing General Anesthesia: A Prospective, Randomized, and Controlled Trial. J Clin Med. 2018;7(9). https://doi.org/10.3390/jcm7090284.

39. Dehghan F, Jalali R, Bashiri H. The effect of virtual reality technology on preoperative anxiety in children: a Solomon four-group randomized clinical trial. Perioperative Medicine. 2019;8:5. https:// doi.org/10.1186/s13741-019-0116-0.

40. Ryu JH, Oh AY, Yoo HJ, Kim JH, Park JW, Han SH. The effect of an immersive virtual reality tour of the operating theater on emergence delirium in children undergoing general anesthesia: A randomized controlled trial. Paediatr Anaesth. 2019;29(1):98-105. https://doi.org/10.1111/pan.13535.

41 •. Trost Z, France C, Anam M, Shum C. Virtual reality approaches to pain: toward a state of the science. Pain. 2021;162(2):325-31. https://doi.org/10.1097/j.pain.0000000000002060 This is a very important paper that describes the recent evidence about VR approaches to pain and the authors propose a conceptual framework (i.e., heuristic model) that "aims to facilitate a language and critical examination of the key elements that drive VR effects on pain experience".

42. Mutterlein J. The three pillars of virtual reality? Investigating the roles of immersion, presence, and interactivity. 2018. 10.24251/ HICSS.2018.174.

43. Witmer BG, Singer MJ. Measuring presence in virtual environments: A presence questionnaire. Presence Teleop Virt. 1998;7(3):225-40. https://doi.org/10.1162/105474698565686.

44. Eijlers R, Utens EM, Staals LM, de Nijs PF, Berghmans JM, Wijnen RM, et al. Meta-analysis: systematic review and metaanalysis of virtual reality in pediatrics: effects on pain and anxiety. Anesth Analg. 2019;129(5):1344-53.

45. Malloy KM, Milling LS. The effectiveness of virtual reality distraction for pain reduction: a systematic review. Clin Psychol Rev. 2010;30(8):1011-8. https://doi.org/10.1016/j.cpr.2010.07.001.

46. Green BN, Johnson CD, Adams A. Writing narrative literature reviews for peer-reviewed journals: secrets of the trade. J Chirop Med. 2006;5(3):101-17. https://doi.org/10.1016/s0899-3467(07) 60142-6.

47. Park JW, Nahm FS, Kim JH, Jeon YT, Ryu JH, Han SH. The Effect of Mirroring Display of Virtual Reality Tour of the Operating Theatre on Preoperative Anxiety: A Randomized Controlled Trial. IEEE J Bio Health Infor. 2019;23(6):2655-60. https://doi.org/10. 1109/jbhi.2019.2892485.

48. Hashimoto Y, Chaki T, Hirata N, Tokinaga Y, Yoshikawa Y, Yamakage M. Video glasses reduce preoperative anxiety compared with portable multimedia player in children: a randomized controlled trial. J PeriAnesthesia Nursing. 2020;35(3):321-5.

49. Jung MJ, Libaw JS, Ma K, Whitlock EL, Feiner JR, Sinskey JL. Pediatric distraction on induction of anesthesia with virtual reality 
and perioperative anxiolysis: a randomized controlled trial. Anesth Analg. 2020;132:798-806. https://doi.org/10.1213/ane. 0000000000005004 .

50. Kain ZN, Mayes LC, Cicchetti DV, Bagnall AL, Finley JD, Hofstadter MB. The Yale Preoperative Anxiety Scale: how does it compare with a "gold standard"? Anesth Analg. 1997;85(4):7838. https://doi.org/10.1097/00000539-199710000-00012.

51. Kain ZN, Mayes LC, Cicchetti DV, Caramico LA, Spieker M, Nygren MM, et al. Measurement tool for preoperative anxiety in young children: the Yale Preoperative Anxiety Scale. Child Neuropsychology. 1995;1(3):203-10. https://doi.org/10.1080/ 09297049508400225.

52. Gupta A, Joseph TJ. Use of virtual reality as a surrogate for parental presence during anesthetic induction: a case report. A A Pract. 2019;13(12):454-6. https://doi.org/10.1213/xaa. 0000000000001114 .

53. Libaw JS, Sinskey JL. Use of augmented reality during inhaled induction of general anesthesia in 3 pediatric patients: a case report. A A Pract. 2020;14(7):e01219. https://doi.org/10.1213/xaa. 0000000000001219.

54. Vrancken J, De Gryse L, Spooren AI. HospiAvontuur: development of a serious game to help young children and their parents during the preparation for an admission at the hospital for elective surgery. Behav Inform Technol. 2019:1-12.

55. Won AS, Bailey J, Bailenson J, Tataru C, Yoon IA, Golianu B. Immersive virtual reality for pediatric pain. Children. 2017;4(7). https://doi.org/10.3390/children4070052.

56. Griffin A, Wilson L, Feinstein AB, Bortz A, Heirich MS, Gilkerson $\mathrm{R}$, et al. Virtual reality in pain rehabilitation for youth with chronic pain: pilot feasibility study. JMIR rehabilitation and assistive technologies. 2020;7(2):e22620. https://doi.org/10.2196/22620.

57. Simons LE, Kaczynski KJ. The Fear Avoidance model of chronic pain: examination for pediatric application. J Pain. 2012;13(9):82735. https://doi.org/10.1016/j.jpain.2012.05.002.

58. Vlaeyen JWS, Linton SJ. Fear-avoidance and its consequences in chronic musculoskeletal pain: a state of the art. Pain. 2000;85(3): 317-32. https://doi.org/10.1016/s0304-3959(99)00242-0.
59. Weerdmeester J, Rooij MV, Harris O, Smit N, Engels RE, Granic I. Exploring the role of self-efficacy in biofeedback video games. Extended Abstracts Publication of the Annual Symposium on Computer-Human Interaction in Play. 2017:453-61. https://doi. org/10.1145/3130859.3131299.

60. Lin HT, Li YI, Hu WP, Huang CC, Du YC. A scoping review of the efficacy of virtual reality and exergaming on patients of musculoskeletal system disorder. J Clin Med. 2019;8(6). https://doi.org/10. 3390/jcm8060791.

61. Mallari B, Spaeth EK, Goh H, Boyd BS. Virtual reality as an analgesic for acute and chronic pain in adults: a systematic review and meta-analysis. J Pain Res. 2019;12:2053-85. https://doi.org/10. 2147/jpr.S200498.

62. Won AS, Tataru CA, Cojocaru CM, Krane EJ, Bailenson JN, Niswonger $\mathrm{S}$, et al. Two virtual reality pilot studies for the treatment of pediatric CRPS. Pain Med. 2015;16(8):1644-7. https://doi.org/ 10.1111/pme.12755.

63. Shiri S, Feintuch U, Weiss N, Pustilnik A, Geffen T, Kay B, et al. A virtual reality system combined with biofeedback for treating pediatric chronic headache-a pilot study. Pain Med. 2013;14(5):621-7. https://doi.org/10.1111/pme.12083.

64. Logan DE, Simons LE, Caruso T, Gold JI, Griffin A, King C, et al. Leveraging VR/AR to combat chronic pain in youth: position paper from the Interdisciplinary Network on Virtual and Augmented (AR/ VR) Technologies for Pain (INOVATE-Pain) Management. J Med Internet Res. 2020. https://doi.org/10.2196/preprints.25916.

65. O’Sullivan B, Alam F, Matava C. Creating low-cost 360-degree virtual reality videos for hospitals: a technical paper on the dos and don'ts. J Med Internet Res. 2018;20(7):e239. https://doi.org/ 10.2196/jmir.9596.

Publisher's Note Springer Nature remains neutral with regard to jurisdictional claims in published maps and institutional affiliations. 